\title{
The Assessment of the Efficiency of Classical and co- Operative Training in Promoting The Participation of Employees of R .P.C in the Field of H.S.E
}

\author{
Elham Mubarak Hassan ${ }^{1}$, Katayoon Varshosaz ${ }^{2}$
}

\begin{abstract}
:
This study aims to evaluate the performance and efficacy of co-operative and classical learning. The study investigates changes in knowledge, attitude, practice and skill of factory workers of RAZI Petrochemical in the field of HSE in 2015. The statistical population in this study is all personnel of RAZI Petrochemical Company. A sample size of 80 persons were selected for evaluation of assumptions. The sample size was divided into two groups of test and control (40 in test group and 40 in control group) both accidentally for. A questionnaire consisting of four parts, knowledge, attitudes, skills and practice was used to collect data in this survey. The reliability of each part was $0.86,0.72,0.89$ and 0.68 respectively. The questionnaires were distributed among test and control groups before training. Then the test and control groups were individually exposed to cooperative and classical training. After a week and then after a month dependent variables were evaluated in test and control groups. The results showed that training in either classic or cooperative method, increases knowledge and attitudes of employees. Knowledge and attitudes before training was similar in both groups ( $\mathrm{P}>0.05)$. After training, the level of knowledge in cooperative method, in a week and a month after training was significantly higher than the classical method $(\mathrm{P}<0.05)$. While in cooperative training group the increasing trend of attitude of personnel was maintained, in classical training group attitude of personnel, a week and a month after training did not change significantly $(\mathrm{P}>0.05)$. The results of evaluation of skill and performance of employees in classical training group a week and a month after training to before training did not change significantly (P>0.05).But The results of evaluation of skill and performance of employees in cooperative training group a week and a month after training to before training changed significantly $(\mathrm{P}<0.05)$. It seems that classical training method has no effect on increasing the performance and skill of employees while cooperative method had significant effect $(\mathrm{P}<0.05)$. Finally, to improve and upgrade within the HSE, a review of the existing guidelines and using experiences of peers and leading international companies and high-quality uninterrupted training in this field is recommended.

Key words: Classical Training, Cooperative Training, BASNEF Method, Hygiene, Safety and the Environment, RAZI Petrochemical
\end{abstract}

Key words: Classical Training, Cooperative Training, BASNEF Method, Hygiene, Safety and the Environment, RAZI Petrochemical

\section{Introduction}

Establishment of HSE management system in organizations and in large and small global companies and industries has always been conducted, based on a series of guidelines which usually have similar structures. Special attention of major global oil and gas and petrochemical organizations and companies to this system indicates its importance in planning and development of products, services and processes, by 
considering their health, safety and environmental considerations. In today's competitive world, many companies have found that they should consider HSE management as an integral part of their organization and they should grant as much importance and value for HSE management as they grant to other managements of the organization. The ultimate goal in HSE management system is protecting people, community, property and environment (Farshad, et al., 2006).

It seems that traditional trainings provided in this area are not efficient without using training models and without using a logical and harmonious approach to create behavioral change. Behavioral theories and social sciences and their models have a unique potential to promote activities in order to reduce the accidents. Theories and models will help the scientists to pay attention to the most suitable areas for change (Heydarnia, 2003).

This study has been conducted to evaluate performance of classic and participatory trainings and their effectiveness on increasing knowledge, attitude and practice of Razi Petrochemical Complex staff, in the field of HSE. Also, this study evaluates the effect of health, safety and the environment training before and after intervention and it compares these factors between the two control and case groups.

\section{Study area}

Razi Petrochemical Complex in a land with an area of 100 hectares is located in the region of Imam Khomeini Port, in northeast of Khoore Musa, $66 \mathrm{~km}$ far from the entrance of the Persian Gulf and at the northern most part of the Gulf. The main feed of this complex is gas which is extracted from seven separate wells, located in Masjed Soleiman. The management of Razi Petrochemical Complex, based on attitudes of, customer-orientation, sustainable development and employee participation, believes that the only way to ensure survival of the organization in tomorrow's market is relying on modern management systems. So in this regard, it considered establishment and utilization of quality management systems, based on the requirements of ISO 9001-2000, environmental requirements based on the requirements of ISO 14001-1996 and occupational health and safety, based on the requirements of OHSAS 18001-1999. With terrific attempts of all of its staff at all organizational levels, this complex has now managed to obtain some international certificates from S.G.S Company and has proven its compliance with the requirements of the above standards. The manager believes that obtaining these certificates doesn't mean reaching to the destination, but it means getting into the path of continuous improvement, in order to further fulfill their effectiveness in the organization.

\section{Knowledge}

Shoots says: "knowledge is an awareness that guides actions in daily life and daily life demonstrates itself as a fact which is interpreted by humans and it is as an interrelated and coherent world which is mentally meaningful to them" (Berger and Luckmann, 1997). 


\section{Organizational performance}

Performance and its related concepts are mainly associated with the area of soft and theoretical sciences. Therefore, due to the relativity of principles, laws and theories, various study and research resources provide different perspectives on the definition of a humane and social concept. In fact, performance is measurable results, decisions and organizational measures that represent the level of success and obtained achievements.

Costs are considered as a central part of performance; however, performance almost encompasses any competitive purpose and spiritual excellence such as reliability, flexibility, quality and speed (Tangen, 2004).

\section{Attitude}

Attitude is a hypothetical structure, because it is not visible directly, but it is mostly associated with behavioral and verbal remarks (Azerbaijani et al., 2006). Due to the importance of attitudes in people's lives, some experts believe that "attitude" is the main topic of social psychology and they define it as the study of the attitudes of people (Karimi, 2000); so that according to some researchers, the concept of attitude is probably the most significant and essential concept in social psychology (Allport, 1935, quoting from Gawronski, 2007).

Despite the importance of attitude, social psychology has experienced numerous debates about providing an appropriate definition to it. However, in the last decades of the twentieth century, these debates are declining. One definition that is probably more comprehensive than others is offered by Cambert and his colleagues: "Attitude is a relatively fixed method in thought, feeling and behavior towards individuals, groups and social issues or somewhat more broadly, it is any incident in one's ambient" (Torkan and Kajbaf, 2008).

\section{Skill}

Since skills are very diverse, it is pretty difficult to offer a definition for skill to be applicable for all the related items. E.R. Guthrie (1952) was a psychologist who defined skill in a way that his definition encompasses its important characteristics. According to him, skill is a capability which can lead to success, with a certain confidence and by spending a minimum of energy or working time.

Table1. Person - hours of training in HSE unit, during four years

\begin{tabular}{|c|c|c|c|c|c|c|c|c|c|c|c|c|c|}
\hline $\begin{array}{l}\text { Cou } \\
\text { rse }\end{array}$ & \multicolumn{3}{|r|}{2011} & \multicolumn{3}{|r|}{2012} & \multicolumn{3}{|r|}{2013} & \multicolumn{4}{|r|}{2014} \\
\hline $\begin{array}{l}\text { H.S. } \\
\text { E }\end{array}$ & $\begin{array}{r}\text { Num } \\
\text { ber } \\
\text { of } \\
\text { cours } \\
\text { es }\end{array}$ & $\begin{array}{r}\text { Pers } \\
\text { ons }\end{array}$ & $\begin{array}{l}\text { Pers } \\
\text { on - } \\
\text { hour } \\
\mathrm{s} \text { of } \\
\text { train } \\
\text { ing }\end{array}$ & $\begin{array}{r}\text { Num } \\
\text { ber } \\
\text { of } \\
\text { cours } \\
\text { es }\end{array}$ & $\begin{array}{r}\text { Pers } \\
\text { ons }\end{array}$ & $\begin{array}{l}\text { Pers } \\
\text { on - } \\
\text { hour } \\
\mathrm{s} \text { of } \\
\text { train } \\
\text { ing }\end{array}$ & $\begin{array}{r}\text { Num } \\
\text { ber } \\
\text { of } \\
\text { cours } \\
\text { es }\end{array}$ & $\begin{array}{r}\text { Pers } \\
\text { ons }\end{array}$ & $\begin{array}{l}\text { Pers } \\
\text { on - } \\
\text { hour } \\
\mathrm{s} \text { of } \\
\text { train } \\
\text { ing }\end{array}$ & $\begin{array}{r}\text { Num } \\
\text { ber } \\
\text { of } \\
\text { cours } \\
\text { e A }\end{array}$ & & $\begin{array}{r}\text { son } \\
\mathrm{s}\end{array}$ & $\begin{array}{r}\text { Perso } \\
\mathrm{n} \quad- \\
\text { hours } \\
\text { of } \\
\text { traini } \\
\text { ng }\end{array}$ \\
\hline $\begin{array}{r}\text { Tot } \\
\text { al } \\
\end{array}$ & 44 & 935 & 6814 & 51 & 2641 & $\begin{array}{r}1831 \\
0\end{array}$ & 36 & 1540 & $\begin{array}{r}1062 \\
4\end{array}$ & & 53 & $\begin{array}{r}286 \\
0\end{array}$ & $\begin{array}{r}1181 \\
7\end{array}$ \\
\hline
\end{tabular}




\section{Statistical population and sampling method}

Statistical population in this study includes all the Razi Petrochemical Company staff. Considering that this study is a pilot study, 80 personnel were randomly selected from the study population to select the sample size and in order to test the hypotheses and they were randomly divided into two classic and participatory groups (40 people in classic group and 40 in participatory group).

\section{Sampling method}

In order to select the staff, at first a list of their names was provided and each of them was given a number. Then, by using simple random sampling method, 80 of them who intended to participate in the study were selected and in the final step, they were divided randomly into two groups of 40 people.

\section{Data collection tool}

Data collection tool in this study was a questionnaire consisting of five parts. The first part of questionnaire was related to the demographic variables of staff, the second part consisted of 10 questions which measured the knowledge of staff in the environment of hot and cold works.

\section{Data analysis method}

In this study, after coding the questions, data were inserted into the computer and they were analyzed through using SPSS-16 software. In this study, items such as frequency distribution table, charts, means, standard deviation and proportions were used o describe and interpret the results, based on the study objectives. Wilcoxon test was used to compare the mean of staff scores, within each group, before and after trainings. Also, Mann-Whitney test was used to compare the mean scores, in each of the phases before and after training. Since the distribution of scores was not normal and the variances were not equal; so, non-parametric tests were used.

This study was conducted at Razi Petrochemical Company. Participatory and classic training courses were conducted separately, during two consecutive weeks and they were conducted for each group, within two three-hour sessions.

\section{Different steps of implementation include:}

\section{Introducing training course topics:}

Training Department of Razi Petrochemical Company was asked about the mechanism of receiving topics and training material, teaching practices and training methods.

3. Selecting training subjects, in consultation with the Training Department of Razi Petrochemical Company

After studying Razi Petrochemical Company and trying to find a subject which is needed for Razi Petrochemical Company personnel and also after consultation with professors and advisors, cold and hot permits were selected as the subject of training course.

HSE management programs always emphasize on taking preventive measures. 
In petrochemical industries, due to the high direct and indirect costs of accidents, occupational diseases and environmental pollutions, utilizing preventive measures and mechanisms has an undeniable importance.

Work permit system is one of the most important mechanisms in this regard.

\section{- hot work}

In hot work used or created heat can ignite liquids, vapors and combustible gases or any other combustible material.

\section{- cold work}

Those works which are not in the range of hot work are called cold works. For example, opening the door of a container (or a manhole) and entering into it to clean, repair, inspect or open a valve or fitting, etc.

4. Designing questionnaires of knowledge, attitude, performance and skill:

The instructions of hot and cold permits, available in Razi Petrochemical Company were used to design the questionnaires.

5. Distributing questionnaires and completing them by the case and control groups:

Pre-training questionnaires were filled out by both groups and were collected and analyzed by researcher.

6. Implementation of training in two groups, with two classic and participatory approaches:

Both groups were separately trained by using classic and participatory approaches.

7. Completing the questionnaires again by both groups, after one week, and also one month after training:

Classic and participatory training groups filled out the questionnaires after one week and again one month after training and then the questionnaires were collected and analyzed by researcher.

8. Analyzing the questionnaires and evaluating the effectiveness of training

Eventually, the questionnaires were collected, analyzed and evaluated.

3-7 evaluation of the amount of toxic, corrosive and irritant substances in the ambient air:

Chemical substances, based on the damage which can impose to human beings are generally divided into the following categories:

- Inflammatory and irritants

- Asphyxiants

- Anaesthetics and narcotics

\section{Teaching methods}

Teaching methods which were selected for hot and cold permits according to the research subject include: participatory method (future workshop method) and classic method. Training sessions were held in two 3-hour sessions for each group. In the classic method, training was conducted through using blackboard and slides.

In this study, the workshop was held in Razi Petrochemical Company. All the participants were the staff of this company and they faced no limitation in expressing their ideas and thoughts, during the study. 
The first phase of future workshop which was held in Razi Petrochemical Company was the preparation phase, during which it was necessary to provide some pre-requisites in order to engage participants and to take advantage of their potentials in solving the problem. These pre-requisites included:

1) Information: informing all the participants about all the consequences

2) Knowledge: in other words, enabling them to provide ideas and solutions on problem

3) Motivation: creating a strong internal force, so that participants themselves acquire necessary and sufficient willingness to solve the problem (Mohammed fam et al., 2004).

Future workshop (FW) method was used to train the participatory group. This method is performed in five phases as follows:

In the first phase, the subject is selected with providing explanations on safety, accident and the role of permits. At the end of this phase, with the participation of all participants, the desired subject for discussion will be selected.

In the second phase, the experimental or critical phase begins. At this phase, problems related to the selected subjects were listed. The aim of this phase was to collect important issues and problems which participants experienced in hot and cold permits. At this stage, the attendees will be asked to express a causing or effective problem in the subject in one sentence. This phase continued until none of the participants could enumerate any cause. At this point, the views of people were registered on white board, without applying any change. By the end of this phase, all participants were given a piece of paper and they were asked to select three problems in order of their importance.

At the end of the experimental phase, the participants were asked to participate in one of three groups, based on their personal interests and their experiences.

After this phase, fantasy phase began. The main objective of this phase was to collect solutions to address the causes of mentioned problems in the previous phase, regardless of possible limitations. In the fantasy phase, everything is assumed to be possible and no organizational, economic or personnel limitation has been considered to be possible.

By the end of the fantasy phase, strategy phase begins. At this stage, the participants were asked to review the solutions listed in the fantasy phase, consider all the limitations and to select the best solution by using the utility and feasibility table (Mohammad fam et al., 2013).

The last phase of future workshop method is administrative and follow-up phase which aims to implement the proposed solutions and to monitor its implementation closely.

\section{Results:}

\section{Descriptive characteristics of study population}

Table2 shows the results of the Mann-Whitney test on comparing the age and work experience of participants

Table2. Frequency distribution of participants in terms of background variables and for each of the training groups

\begin{tabular}{|r|r|r|r|r|}
\hline \multirow{2}{*}{$\begin{array}{c}\text { Significance level } \\
\text { (Mann-Whitney test) }\end{array}$} & \multicolumn{3}{|c|}{ training groups } & \multirow{4}{*}{ Variables } \\
\cline { 2 - 4 } & Standard deviation & Mean & Standard deviation & Mean \\
\end{tabular}




\begin{tabular}{|r|r|r|r|r|r|}
\hline $0 / 051$ & $6 / 36$ & $30 / 80$ & $9 / 94$ & $35 / 27$ & Age \\
\hline $0 / 196$ & $5 / 65$ & $6 / 99$ & $10 / 35$ & $10 / 62$ & Work experience \\
\hline
\end{tabular}

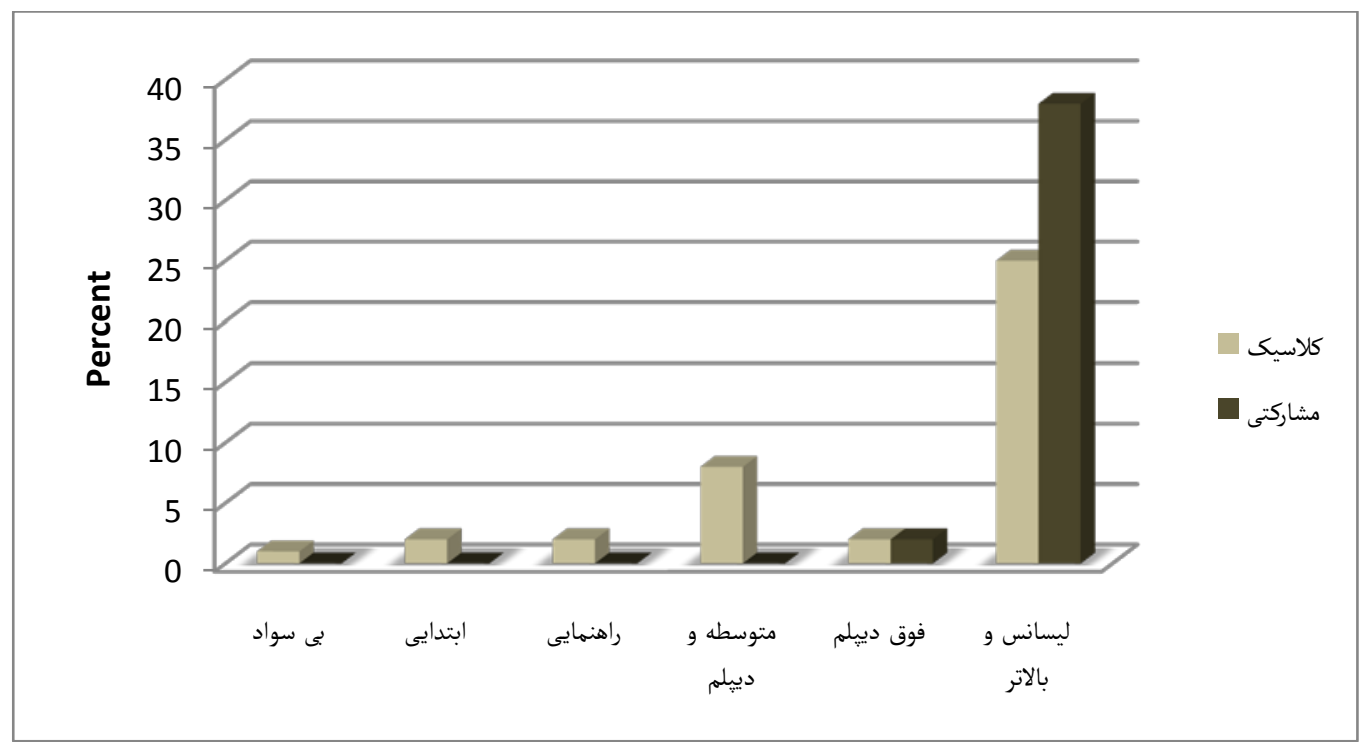

Chart 1: Distribution of studied staff, in terms of their education in two training groups

Table3: Frequency distribution of educational level of participants, in two classic and participatory groups

\begin{tabular}{|r|r|r|r|l|}
\hline \multicolumn{2}{|l|}{ Participatory } & \multicolumn{2}{|l|}{ Glassic } \\
\hline Percent & Number & Percent & \multicolumn{2}{|c|}{ Number } \\
\hline 0 & 0 & $2 / 5$ & 1 & Illiterate \\
\hline 0 & 0 & $5 / 0$ & 2 & Elementary \\
\hline 0 & 0 & $5 / 0$ & 2 & Secondary school \\
\hline $5 / 0$ & 0 & $20 / 0$ & 8 & High school \\
\hline $95 / 0$ & 2 & $5 / 0$ & 2 & Associate Degree \\
\hline & 38 & $62 / 5$ & 25 & Bachelor's Degree or higher \\
\hline
\end{tabular}

Chart 1 and the above table show educational level of participants in two classic and participatory groups. As the results of above table indicate, the number of people with bachelor or higher degree in participatory group is more. Fisher's exact test showed that educational level of participants in these two groups are significantly different ( $p$ value $=0.001)$.

\section{Changes in participant's knowledge scores, in two training groups:}


Table 4: Comparison of participant's knowledge scores, during the study period for two training groups

\begin{tabular}{|c|c|c|c|c|c|}
\hline \multirow{2}{*}{$\begin{array}{r}\text { Comparing two } \\
\text { training groups } \\
\text { (Mann-Whitney } \\
\text { test) }\end{array}$} & \multicolumn{2}{|l|}{ Participatory } & \multicolumn{2}{|l|}{ Classic } & \multirow{2}{*}{$\begin{array}{l}\text { Groups } \\
\text { Knowledge }\end{array}$} \\
\hline & $\begin{array}{l}\text { Standard } \\
\text { deviation }\end{array}$ & Mean & $\begin{array}{l}\text { Standard } \\
\text { deviation }\end{array}$ & Mean & \\
\hline $\begin{array}{r}Z=-0.628 \\
P=0.530\end{array}$ & $1 / 86$ & $5 / 50$ & $1 / 60$ & $4 / 90$ & Before intervention \\
\hline $\begin{array}{r}Z=-0.503 \\
P=0.612\end{array}$ & $0 / 89$ & $8 / 50$ & $0 / 92$ & $8 / 10$ & $\begin{array}{l}\text { One week after } \\
\text { intervention }\end{array}$ \\
\hline $\begin{aligned} Z & =-0.473 \\
P & =0.636\end{aligned}$ & $0 / 54$ & $9 / 10$ & $1 / 12$ & $8 / 90$ & $\begin{array}{l}\text { One month after } \\
\text { intervention }\end{array}$ \\
\hline & \multicolumn{2}{|c|}{$Z=-5.042, p<0.001$} & \multicolumn{2}{|c|}{$Z=-5.206, p<0.001$} & $\begin{array}{l}\text { Comparing past situation, } \\
\text { with one week after } \\
\text { training (Wilcoxon) }\end{array}$ \\
\hline & \multicolumn{2}{|c|}{$Z=-5.530, p<0.001$} & \multicolumn{2}{|c|}{$Z=-5.273, p<0.001$} & $\begin{array}{l}\text { Comparing past situation, } \\
\text { with one month after } \\
\text { training (Wilcoxon) }\end{array}$ \\
\hline & \multicolumn{2}{|c|}{$\mathrm{Z}=-4.577, \mathrm{p}<0.001$} & \multicolumn{2}{|c|}{$\mathrm{Z}=-3.907, \mathrm{p}<0.001$} & $\begin{array}{l}\text { Compare one week and } \\
\text { one month after training } \\
\text { (Wilcoxon) }\end{array}$ \\
\hline
\end{tabular}

The results show that whether the training is classic or participatory, it will increase the level of knowledge of staff. However these results are not unexpected. The remarkable result is that participatory method has been more effective compared to classic method in increasing the level of knowledge of staff.

The results of the above table shows that the level of knowledge of staff before training was equal in both groups $(\mathrm{P}=0.530)$ and after the training, the level of knowledge in classic and participatory training methods are not significantly different (after a week of $\mathrm{P}=0.612$, and after a month, $\mathrm{P}=0.636$ ).

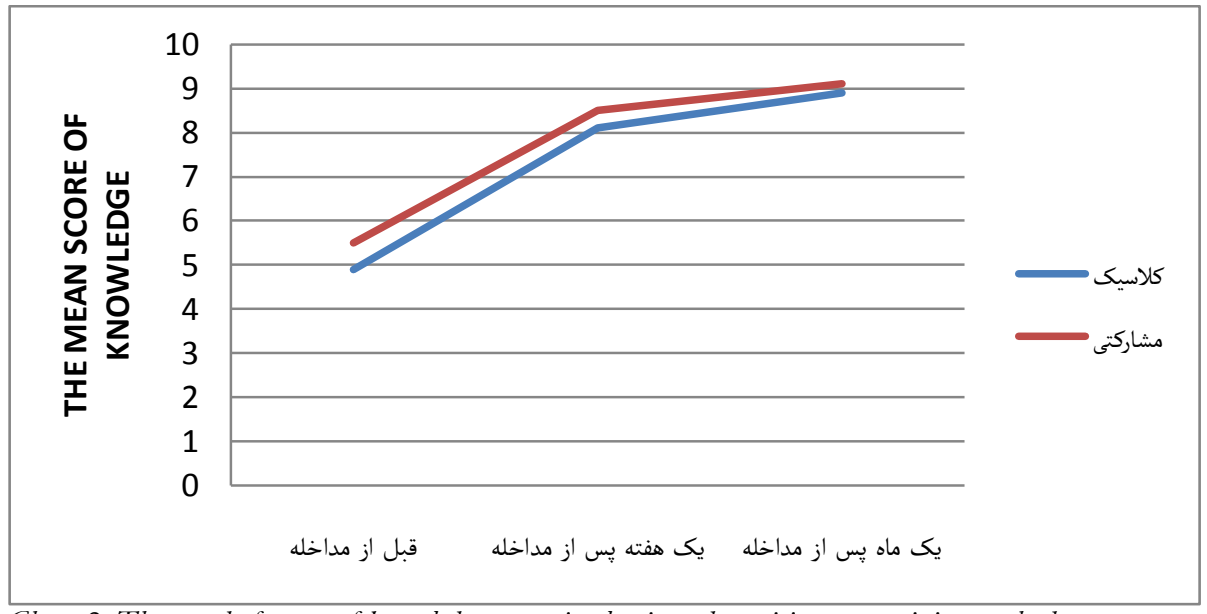

Chart 2: The trend of mean of knowledge scores in classic and participatory training methods 


\section{Changes in participant's attitude scores, in two training groups:}

Table 5: Comparison of participant's attitude scores, during the study period for two training groups

\begin{tabular}{|c|c|c|c|c|c|}
\hline \multirow{2}{*}{$\begin{array}{l}\text { Comparing two } \\
\text { training groups } \\
\text { (Mann-Whitney test) }\end{array}$} & \multicolumn{2}{|l|}{ Participatory } & \multicolumn{2}{|l|}{ Classic } & \multirow[b]{2}{*}{ Attitude } \\
\hline & $\begin{array}{l}\text { Standard } \\
\text { deviation }\end{array}$ & Mean & $\begin{array}{l}\text { Standard } \\
\text { deviation }\end{array}$ & Mean & \\
\hline $\begin{array}{l}Z=-0.231 \\
P=0.818\end{array}$ & $1 / 97$ & $6 / 75$ & $1 / 86$ & $6 / 85$ & Before intervention \\
\hline $\begin{array}{l}Z=-0.269 \\
P=0.788\end{array}$ & $1 / 00$ & $7 / 35$ & $0 / 98$ & $7 / 40$ & $\begin{array}{l}\text { One week after } \\
\text { intervention }\end{array}$ \\
\hline \multirow[t]{4}{*}{$\begin{array}{l}Z=-2.270 \\
P=0.023\end{array}$} & $1 / 17$ & $8 / 05$ & $1 / 08$ & $7 / 57$ & $\begin{array}{l}\text { One month after } \\
\text { intervention }\end{array}$ \\
\hline & \multicolumn{2}{|c|}{$Z=-1.958, p<0.001$} & \multicolumn{2}{|c|}{$\mathrm{Z}=-2.015, \mathrm{p}<0.001$} & $\begin{array}{l}\text { Comparing past situation, } \\
\text { with one week after } \\
\text { training (Wilcoxon) }\end{array}$ \\
\hline & \multicolumn{2}{|c|}{$Z=-3.351, p<0.001$} & \multicolumn{2}{|c|}{$\mathrm{Z}=-1.809, \mathrm{p}<0.001$} & $\begin{array}{l}\text { Comparing past situation, } \\
\text { with one month after } \\
\text { training (Wilcoxon) }\end{array}$ \\
\hline & \multicolumn{2}{|c|}{$Z=-2.838, p<0.001$} & \multicolumn{2}{|c|}{$Z=-0.599, p=0.549$} & $\begin{array}{l}\text { Compare one week and } \\
\text { one month after training } \\
\text { (Wilcoxon) }\end{array}$ \\
\hline
\end{tabular}

The results show that both classic and participatory training methods can increase the level of attitude of staff (Wilcoxon test). In other words, Wilcoxon test indicated that the level of attitude of people one week and one month after training is significantly different comparing to their attitude before training. Also in the two groups of participatory and classic training, the increasing trend of the attitude of the personnel has been maintained.

The results of the above table and Chart 4-3 shows that the attitude of staff before training was equal in both groups $(\mathrm{P}=0.818)$ and one month after training, the level of attitude of staff in the participatory training method was significantly more than classic method $(\mathrm{P}=0.023)$. 


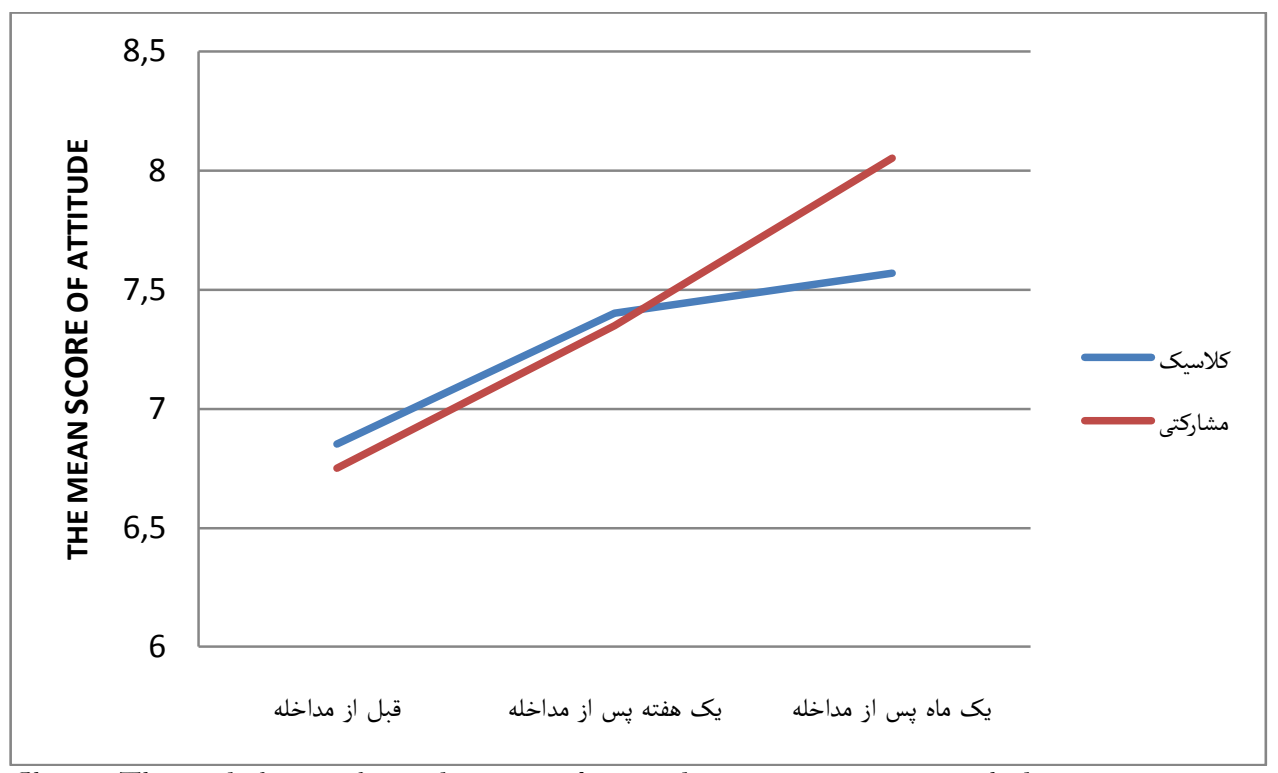

Chart 3: The trend of mean of attitude scores in classic and participatory training methods

\section{Changes in participant's performance scores, in two training groups:}

Table 6: Comparison of participant's performance scores, during the study period for two training groups

\begin{tabular}{|c|c|c|c|c|c|}
\hline \multirow{2}{*}{$\begin{array}{l}\text { Comparing two } \\
\text { training groups } \\
\text { (Mann-Whitney } \\
\text { test) }\end{array}$} & \multicolumn{2}{|l|}{ Participatory } & \multicolumn{2}{|l|}{ Classic } & \multirow[b]{2}{*}{ Performance } \\
\hline & $\begin{array}{l}\text { Standard } \\
\text { deviation }\end{array}$ & Mean & $\begin{array}{l}\text { Standard } \\
\text { deviation }\end{array}$ & Mean & \\
\hline $\begin{array}{r}Z=-4.620 \\
P=0.000\end{array}$ & $4 / 79$ & $14 / 26$ & $5 / 10$ & $11 / 52$ & Before intervention \\
\hline $\begin{aligned} Z & =-1.453 \\
P & =0.146\end{aligned}$ & $3 / 67$ & $19 / 05$ & $4 / 86$ & $17 / 32$ & One week after intervention \\
\hline $\begin{aligned} Z & =-5 / 250 \\
P & =0.0000\end{aligned}$ & $3 / 49$ & $23 / 37$ & $4 / 85$ & $17 / 97$ & $\begin{array}{l}\text { One month after } \\
\text { intervention }\end{array}$ \\
\hline & \multicolumn{2}{|c|}{$\mathrm{Z}=-4.466, \mathrm{p}<0.001$} & \multicolumn{2}{|c|}{$\mathrm{Z}=-3.996, \mathrm{p}<0.001$} & $\begin{array}{r}\text { Comparing past situation, } \\
\text { with one week after training } \\
\text { (Wilcoxon) }\end{array}$ \\
\hline & \multicolumn{2}{|c|}{$\mathrm{Z}=-4 / 463, \mathrm{p}<0.001$} & \multicolumn{2}{|c|}{$\mathrm{Z}=-3 / 820, \mathrm{p}<0.001$} & $\begin{array}{r}\text { Comparing past situation, } \\
\text { with one month after training } \\
\text { (Wilcoxon) }\end{array}$ \\
\hline & \multicolumn{2}{|c|}{$\mathrm{Z}=-4.426, \mathrm{p}<0.001$} & \multicolumn{2}{|c|}{$Z=-0.559, p=0.576$} & $\begin{array}{l}\text { Compare one week and one } \\
\text { month after } \begin{array}{r}\text { training } \\
\text { (Wilcoxon) }\end{array}\end{array}$ \\
\hline
\end{tabular}


Obtained results indicate that the level of performance of participants in classic and participatory training groups one week and one month after the training has significantly changed comparing with pre-training situation.

On the other hand, the results of the above table shows that one week after training, the level of performance of staff in the participatory training method was significantly more than classic method $(\mathrm{P}=0.000)$.

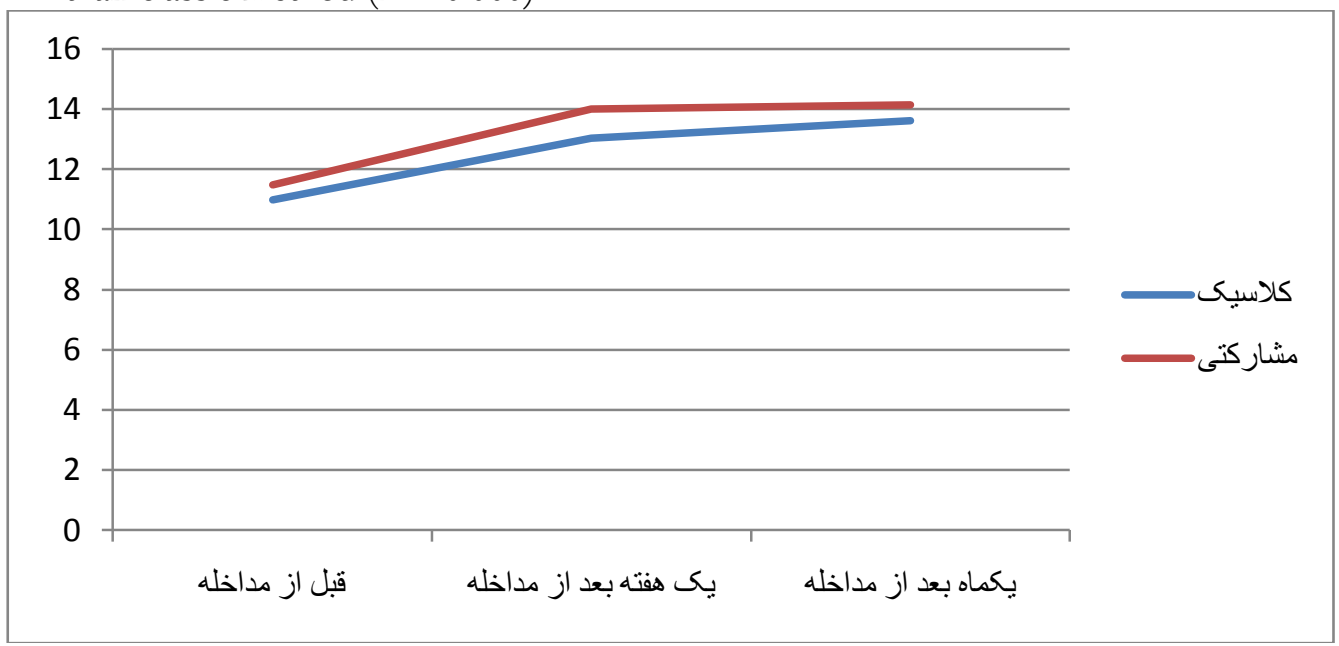

Chart 4: The trend of mean of performance scores in classic and participatory training methods

According to the results, we can see that one month after the training course, the level of performance of staff in two classic and participatory training groups has increased.

\section{Changes in participant's skill scores, in two training groups:}

Table 6: Comparison of participant's skill scores, during the study period for two training groups

\begin{tabular}{|c|c|c|c|c|c|}
\hline \multirow{2}{*}{$\begin{array}{l}\text { Comparing two training } \\
\text { groups (Mann-Whitney } \\
\text { test) }\end{array}$} & \multicolumn{2}{|c|}{ Participatory } & \multicolumn{2}{|l|}{ Classic } & \multirow[b]{2}{*}{ Skill } \\
\hline & $\begin{array}{l}\text { Standard } \\
\text { deviation }\end{array}$ & Mean & $\begin{array}{l}\text { Standard } \\
\text { deviation }\end{array}$ & Mean & \\
\hline $\begin{array}{r}Z=-1.699 \\
P=0.089\end{array}$ & $0 / 95$ & $1 / 64$ & $1 / 03$ & $1 / 26$ & Before intervention \\
\hline $\begin{aligned} Z & =-1.166 \\
P & =0.244\end{aligned}$ & $1 / 08$ & $2 / 57$ & $0 / 90$ & $2 / 09$ & One week after intervention \\
\hline \multirow[t]{4}{*}{$\begin{array}{r}Z=-2.900 \\
P<0.001\end{array}$} & $0 / 72$ & $3 / 76$ & 0/91 & $3 / 27$ & One month after intervention \\
\hline & \multicolumn{2}{|c|}{$Z=-3.402, p<0.001$} & \multicolumn{2}{|c|}{$Z=-4.907, P<0.001$} & $\begin{array}{l}\text { Comparing past situation, with } \\
\text { one week after training } \\
\text { (Wilcoxon) }\end{array}$ \\
\hline & \multicolumn{2}{|c|}{$Z=-4.571, p<0.001$} & \multicolumn{2}{|c|}{$Z=-4.571, P<0.001$} & $\begin{array}{l}\text { Comparing past situation, with } \\
\text { one month after training } \\
\text { (Wilcoxon) }\end{array}$ \\
\hline & \multicolumn{2}{|c|}{$Z=-2.004, P<0.001$} & \multicolumn{2}{|c|}{$Z=-2.004, P<0.001$} & $\begin{array}{l}\text { Compare one week and one } \\
\text { month after training (Wilcoxon) }\end{array}$ \\
\hline
\end{tabular}


In participatory and classic methods, it was found that such training methods can significantly improve staff skill.

Both of training methods, even one week and one month after the training have had their positive impacts on improvement of participants' skill, in comparison to pretraining situation $(\mathrm{p}<0.001)$.

Also, by considering the results of the above table we can say that participatory training method has been more effective on participants' skill, in comparison to classic method (Figure 4-5).

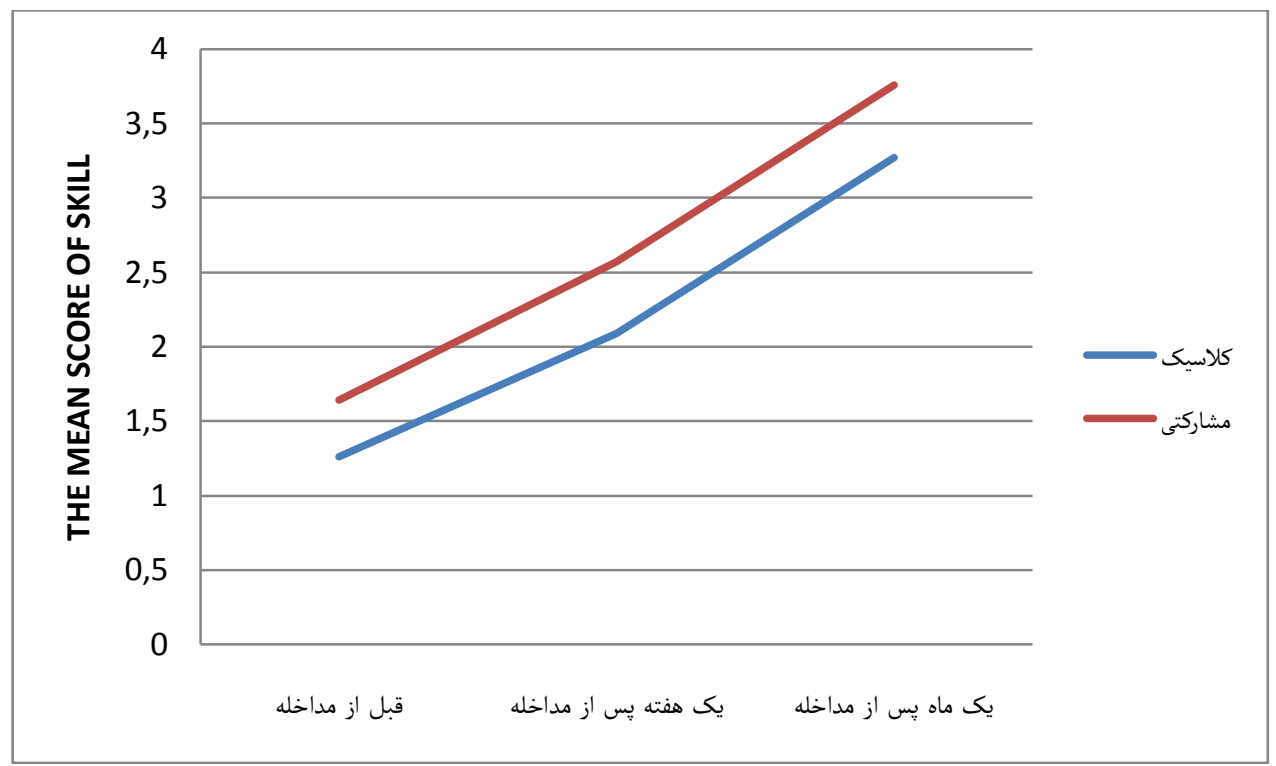

Chart 4: The trend of mean of skill scores in classic and participatory training methods

In implementation of training interventions, using behavioral theories such as Basnef model can create potentials to enhance effectiveness of these interventions. Basnef model is used to meet the needs of health education in developing countries. This model is used in the study of behavior and planning to change it and also in determining the factors which are effective in decision makings. In this model, items such as attitude toward behavior, norms, social pressures, behavior intention and enabling factors effective in behaviors, such as skill, time and cost are studied.

This study was conducted to evaluate the performance of classic and participatory training by using Basnef model and to assess effectiveness of these trainings on enhancement of knowledge, attitude, performance and skill of Razi Petrochemical Complex staff, in the field of HSE and to analyze the results.

\section{Analysis Results}

The results of this study showed that there was no significant difference between participants in the two groups, in terms of age ( $p$-value $=0.674$ ). 
Although the number of participants with a bachelor or a higher degree in classic group has been more than participatory group, but there was no significant difference between the two groups in terms of educational level ( $\mathrm{p}$-value $=0.001)$.

\section{Knowledge}

The first objective of the present study was to compare the average knowledge in two groups of classic and participatory training methods, before the intervention and one week and also one month after the intervention. In this regard, findings indicated that there is a statistically significant positive difference between the mean score of knowledge in classic and participatory groups, before intervention (training) and one week and one month after the intervention ( $\mathrm{p}$-value $<0.05)$. It seems that this issue is due to the applied training interventions; because this result is consistent with the result of the study conducted by Taghdisi et al (2008) entitled "investigating the impact of training interventions on the safety performance of Zob Ahan Esfahan coke making workers, by using Basnef model" as well as another study conducted by Solhi et al (2010).

\section{Attitude}

Another objective of the present study was to compare the mean attitude in two groups of classic and participatory training methods, before and after the intervention. The findings indicated that there is a significant positive difference between the mean score of attitude in classic group, before intervention and one week and one month after the intervention ( $\mathrm{p}$-value $<0.05)$. However, this increasing trend in the attitude is not observable between one week after intervention and one month after intervention ( $\mathrm{p}$ value $>0.05)$.

Also, there is a significant positive difference between the mean score of attitude in participatory group, before intervention and one week and one month after the intervention ( $p$-value $<0.05)$ and this interesting trend from one week to one month after the intervention has been maintained significant. This part of the study results is also consistent with the results of Taghdisi et al (2008). Their findings indicated that immediately after the intervention and one month after the intervention, the attitude score of Zob Ahan Esfahan coke making workers has significantly increased.

\section{Performance}

According to the results, there is a significant positive difference between the mean score of performance in classic group, before intervention and one week and one month after the intervention ( $\mathrm{p}$-value $<0.05)$ and there is no significant difference between one week after intervention and one month after intervention ( $\mathrm{p}$-value $>0.05$ ). Also, there is a significant positive difference between the mean score of performance in participatory group, before intervention and one week and one month after the intervention ( $\mathrm{p}$-value $<0.05)$ and this interesting trend from one week to one month after the intervention has not continued ( $\mathrm{p}$-value $>0.05)$. 


\section{Skill}

Based on the results, there is a significant positive difference between the mean score of skill in classic group, before intervention and one week and one month after the intervention ( $p$-value $<0.05)$ and there is no significant difference between one week after intervention and one month after intervention ( $p$-value $>0.05)$. Thus, in classic and participatory methods, we can see that such training methods can significantly improve staff skill and both of applied training groups, even one week and one month after training, have maintained their positive impact in improvement of participants' skill ( $\mathrm{p}<$ 0.001).

Also, there is a significant difference in status of staff skill between one week after intervention and one month after intervention ( $p$-value $>0.05$ ).

Also, based on the results we can say that participatory training method has been more effective on improvement of participants' skill, comparing with classic method.

\subsection{Executive solutions and suggestions}

The results of the implementation of different phases of FW training method is presented below:

First phase: The output of this phase was selection of subject that was: Why the authorities who are responsible to issue hot and cold permits are not strict and sensitive in full implementation of the relevant instructions?

Second phase: In this phase problems related to insensitivity of permits were mentioned in three general categories of administrative, safety and cultural problems and the most important raised factors included:

1) Lack of supervision of senior managers on permit issuing authorities

2) Neglecting alarms received in this regard

3) The importance of income generation, which in turn expedites the work and defects the licensing process

4) Lack of adequate safety monitoring

5) Lack of comprehensive instructions, regarding issuing hot and cold permits

6) Inadequate and poor quality training in this regard

7) Low level of safety culture in the company

Among these problems, three causes possess the highest scores:

1) Lack of comprehensive instructions, regarding issuing hot and cold permits

2) Low level of safety culture in the company

3) Lack of supervision of senior managers on permit issuing authorities

Third phase: This phase identified several solutions for three categories of above causes and the most important cases included:

\section{Administrative solutions}

1) Reviewing existing instructions

2) Utilizing the experiences of other peer companies

3) Using documents of leading foreign companies 
4) Utilizing experienced people as well as people with relevant knowledge in reviewing the instructions

\section{- Safety solutions}

1) Continuous and high quality trainings in this regard

2) Continuity and suitability of trainings in enhancement of safety culture among personnel

3) Using workshops for issuance of work permits instead of mere theory courses

4) Observing safety principles at work

\section{- Cultural solutions}

1) Organizing safety management courses for managers

2) Convincing managers that staff health and capital are more important than production

3) Management of maintenance operations, based on a suitable scheduling

4) Sending managers to advanced countries to participate in training courses

Fourth phase: In Table 1-2, solutions presented in section 2 are considered as immediate solutions and those presented in section 4 are considered as development solutions and those solutions presented in sections 3 and 1 will not be further studied.

The most important solutions to increase the desirability of issuing licenses for hot and cold work (permits) and raising the level of safety included:

1) Providing practical training to the personnel

2) Encouraging staff to participatory trainings

3) Organizing continuous training courses

4) Increasing systematic safety supervisions

5) Compilation and publication of pamphlets and training materials, on hot and cold permits

6) Organizing safety competitions, based on previously published information and granting prizes to the participants

7) Involving all the operational personnel in licensing courses, regardless of the issue that who will sign the licenses (permits) in the future.

In order to effectively implement the licensing mechanism, it is recommended to review the existing work permit system in the following six areas:

1) Reviewing work permit system

2) Monitoring documentations

3) Implementation of training and determining and updating the competencies

4) Reviewing work permit forms

5) Coordinating and implementation of monitoring

6) Performing isolation

\section{References}

Berger, Peter and Luckmann, Thomas, 1996, "Social Construction of Reality, a thesis in sociology of knowledge", translated by Fariborz Majidi, Tehran, Scientific and Cultural Publishing Company.

Tajvar, Hamid, Ghanbarnejad, Amin, Tajvar, Abdul Hamid, Momeni sarvestani, Marzieh, Abolhassannezhad, Vahide, 2011, "The effect of safety training on promotion of safe behavior of workers", Seventh National Congress of Occupational Health, 2011.

Torkan, H., Kajbaf, M. 2008, Journal of Behavioral Sciences, the first year, the first issue. 
Taghdisi, M. 2006, "Health, Safety and Environment (HSE) Management; a creative approach in sustainable development", Journal of Iran's Occupational Health, issue 3, number 3 and number 4.

Taghdisi, Mohammad Hossein; Madadzadeh, Negin; Shadzi, Shahin; Hassanzadeh, Akbar, 2008, "Investigating the impact of training interventions on the safety performance of Zob Ahan Esfahan coke making workers in 2005, by using Basnef model”, Journal of Iran's Occupational Health, 16 (3): 20-29.

Jalali, Jalil, Reza Ali, Mohammad Bagher; Amirkhni, Reza; Alimoradi, Farhad, 2008, "Comparative study of the impacts of health and safety training, based on current and dynamic methods, on promotion of knowledge and attitude of miners".

Soltani, Iraj (2006), "Interaction of needs assessments and effectiveness of training in learning organizations", Isfahan, publication of pillars of Knowledge.

Sadri, Sadruddin (2004), "Training system for government employees (foundations, principles, strategies and models)", Tehran, Organization of Management and Planning, Department of management development and capital.

Abdollahi, Bijan, Navveh Ebrahim, Abdul Rahim (2007), " Empowering employees: a golden key for human resources management", Tehran: Publication of editing.

Abdollahi, Javad, Ali Pour, Mohammadreza, Eidi, Akbar (2009), "Measuring the effectiveness of training courses", Monthly journal of Tadbir, nineteenth year, No. 200.

Al-Athari A, \& Zairi M (2002), Training evaluation, Journal of European Industrial Training, Vol. 26, No. 5.

Basarab, D \& Root, D.K (1992), The training evaluation process: A practical approach to evaluation , Springer, Vol. 13, No. 2.

Bedingham, K (1997), Proving the effectiveness of training, Industrial and Commercial Training, Vol. 29, No. 3.

Behm, M., 2005. Linking construction fatalities to the design for construction safety concept. Safety Science 43 (8), 589-611.

Brinkerhoff, R (2006), Increasing impact of training investment, Industrial and Commercial Training, Vol. 38 , No. 6.

Canadian Center for Management (2001), A Learning Measurement Tool for the

Government of Canada Instructional Programs, Canadian Center for Management Development.

Cartwright, R. (2003), Training and Development Express, Capstone Publishing, Oxford, United Kingdom. 